\title{
Antecedent Disease Is Less Prevalent in Amyotrophic Lateral Sclerosis
}

\author{
Cassie S. Mitchell $^{\mathrm{a}}$ Sabrina K. Hollinger ${ }^{\mathrm{a}}$ Shivani D. Goswami ${ }^{\mathrm{a}}$ \\ Meraida A. Polak ${ }^{b}$ Robert H. Lee ${ }^{a}$ Jonathan D. Glass ${ }^{b}$ \\ ${ }^{a}$ Department of Biomedical Engineering, Georgia Institute of Technology and Emory University, and ${ }^{b}$ Department \\ of Neurology, School of Medicine, Emory University, Atlanta, Ga., USA
}

\section{Key Words}

Amyotrophic Lateral Sclerosis · Lou Gehrig's disease •

Antecedent condition tion' - the underpinnings of ALS could infer protection to other diseases, possibly via the mechanism hypervigilant regulation or 'too-high' regulatory feedback gains.

(c) 2015 S. Karger AG, Basel

\section{Introduction}

For years, researchers have searched for a demographic, environmental, pathological or other commonality among ALS patients that could explain the disease's seemingly complex etiology. This has led to an array of studies suggesting a potential role for individual antecedent conditions, including cardiovascular $[1,2]$, metabolic [3], neurological [4], and autoimmune factors [5]. Previous studies, typically much smaller in size, have examined a few antecedent conditions [1, 2, 6-8].

In particular, given the apparent hyper-metabolic state that accompanies ALS progression, the role of metabolism and metabolic disease has been of most interest. Overall, results have shown a statistically lower prevalence of cardiovascular disease [2], hypertension $[1,2,6]$, and obesity $[1,9]$. Thyroid disease $[10,11]$ and diabetes $[2,6]$ have been studied to a lesser degree, with limited examination qualitatively showing lower prevalence in ALS. The most studied antecedent condition is high blood cholesterol, also known as hyperlipidemia or hypercho-

\begin{tabular}{|c|c|}
\hline KARGER 125 & $\begin{array}{l}\text { (c) } 2015 \text { S. Karger AG, Basel } \\
1660-2854 / 15 / 0152-0109 \$ 39.50 / 0\end{array}$ \\
\hline $\begin{array}{l}\text { E-Mail karger@karger.com } \\
\text { www.karger.com/ndd }\end{array}$ & $\begin{array}{l}\text { This is an Open Access article licensed under the terms of the } \\
\text { Creative Commons Attribution-NonCommercial 3.0 Un- } \\
\text { ported license (CC BY-NC) (www.karger.com/OA-license), } \\
\text { applicable to the online version of the article only. Distribu- } \\
\text { tion permitted for non-commercial purposes only. }\end{array}$ \\
\hline
\end{tabular}

Cassie S. Mitchell, $\mathrm{PhD}$

Georgia Institute of Technology

313 Ferst Drive

Atlanta, GA 30332 (USA)

E-Mail cassie.mitchell@bme.gatech.edu 
lesterolemia, which also remains the most controversial, with some studies finding a higher [12] others a lower prevalence [6] in ALS patients.

However, numerous other antecedent conditions, such as the possible role of lung, liver, and kidney disease are yet to be examined. Here we present the analysis of the prevalence of a wide variety of antecedent conditions, including liver disease, kidney disease, asthma, chronic obstructive pulmonary disease (COPD), arthritis, non-ALS neurological disease, hypertension, hyperlipidemia, diabetes, obesity, and thyroid disease, in a large ALS clinic population ( $\mathrm{n}=1,288$ patients).

\section{Methods}

We performed a case-control study of antecedent disease in age, gender and geography-matched ALS and control populations. The ALS study population consisted of 1288 patients from the Emory ALS Clinic (Emory University Hospital, Atlanta, Georgia, which is located in southern USA). The control study population consisted of 7,561 participants residing in the same geographical area. The Internal Review Boards of Emory University and Georgia Institute of Technology approved all protocols of this study.

\section{Antecedent Condition Assessment}

The prevalence of hyperlipidemia, diabetes, hypertension, thyroid disease, asthma, chronic obstructive pulmonary disease (COPD), liver disease, kidney disease, arthritis, and non-ALS neurological disease was assessed using a standardized medical history survey administered by specially trained personnel. Briefly, the survey asked if a physician had ever diagnosed or treated the participant with said condition and if it had been subsequently affirmed in the last year. Medical and prescription records were used to verify survey responses. Obesity was assessed using recorded height and body weight to calculate body mass index (BMI). A BMI greater than 30 was considered obese.

\section{Study Populations and Criteria}

Surveyed participants included ALS patients and control subjects who were age 20+ years and resided in the southern United States, as defined by the Center for Disease Control [13]. All ALS participants were patients of the Emory University ALS Clinic. Note that in the geographical region assessed in this study, $45-70 \%$ of the ALS population are seen at one of approximately thirteen ALS specialty clinics [14] of which about one-third are seen at the Emory ALS Clinic. All ALS patients had a confirmed diagnosis of ALS, which included the presence of exclusionary diagnostic tests (MRI, CSF, etc.) and multivisit Emory ALS Clinic assessment by a neurologist. Control subjects with measured body weights that were considered extreme outliers (males less than 126 pounds or greater than 299 pounds and females less than 100 pounds or greater than 274 pounds) were excluded [13].

\section{Statistical Analysis}

The control population was ratio-matched by age and gender to the ALS population to insure equivalent study population distributions (see table 1). A standard odds ratio (OR) statistical test
Table 1. ALS and control population by age and gender

\begin{tabular}{lrc}
\hline Condition & ALS & Control \\
\hline Male & & \\
$\quad$ 20-44 years & 117 & 688 \\
45-64 years & 404 & 2,375 \\
$\quad 65+$ years & 254 & 1,493 \\
$\quad$ All & 775 & 4,556 \\
Female & & \\
20-44 years & 45 & 259 \\
45-64 years & 258 & 1,511 \\
65+ years & 210 & 1,235 \\
$\quad$ All & 513 & 3,005 \\
Total & 1,288 & 7,561 \\
\hline
\end{tabular}

Note that the control population shown was ratio-matched by age and gender to the ALS population to insure equivalent distributions (see Methods).

with a $95 \%$ confidence interval (CI) was used to assess the prevalence of each condition in the ALS population compared to the prevalence of the control population.

\section{Assessment of Other Confounds}

Socio-economic (i.e., income and education) and health care maintenance information (i.e., regular follow-up with a physician) was not available for all subjects. Therefore, in addition to our data, we also examined other published data sets, which had assessed the impact of these confounds on condition prevalence [15-17]. For each data set, we calculated standardized factors of change to determine the maximum possible bias on condition prevalence. The overall calculated maximum bias (a factor of 2) was converted to an odds ratio limit (i.e., an $\mathrm{OR}<0.5$ ) from which the findings of this study could be directly compared (see Discussion).

\section{Results}

Of the 1,396 ALS patients who completed the survey, 1,288 ALS patients met the stated diagnostic criteria. The percentage of ALS patients with at least one known family member with ALS was $5.05 \%$, which is consistent with previously published estimates [18]. The average and standard deviation of ALS onset age was $60.0 \pm 12.2$ for females and $56.9 \pm 12.4$ for males. Thus, we conclude that the ALS population in this study is representative of a typical ALS population [19]. Of the 15,167 control subject surveys meeting inclusion criteria, 7,561 were used to ratio-match the control population distribution to the age and gender distribution as the ALS population. The age and gender distributions of the ALS and control population are shown in table 1. 
Table 2. Associations of ALS with odds of antecedent conditions

\begin{tabular}{ll}
\hline Condition & Odds ratio, $(\mathrm{CI})$ \\
\hline Arthritis & $0.14(0.11,0.18)$ \\
Neurological disease & $0.14(0.07,0.27)$ \\
Liver disease & $0.19(0.10,0.35)$ \\
COPD & $0.23(0.16,0.32)$ \\
Kidney disease & $0.32(0.18,0.57)$ \\
Asthma & $0.39(0.30,0.51)$ \\
Diabetes & $0.47(0.38,0.58)$ \\
Hypertension & $0.56(0.49,0.64)$ \\
Obesity & $0.60(0.49,0.74)$ \\
Hyperlipidemia & $0.62(0.54,0.71)$ \\
Thyroid disease & $0.78(0.60,1.02)$ \\
\hline
\end{tabular}

Parameters are odds ratio (OR) and 95\% confidence interval (CI). The prevalence of each condition is less in ALS compared to the age and gender ratio-matched control condition.

Table 2 compares the prevalence of each condition in the ALS population to the age and gender ratio-matched control population using a statistically calculated odds ratio (OR) with a $95 \%$ confidence interval $(\mathrm{CI})$ given in parentheses. Note that an $\mathrm{OR}=1$ represents an equal prevalence in both the ALS and control populations; an OR $<1$ represents lower prevalence in the ALS population; and an OR $>1$ represents a greater prevalence in the ALS population. The overall average prevalence of each of the assessed conditions is as follows: arthritis (ALS = $5.36 \%$, control $=29.5 \%, \mathrm{OR}=0.14)$; non-ALS neurological disease $(\mathrm{ALS}=0.7 \%$, control $=4.68 \%, \mathrm{OR}=0.14)$; liver disease $(\mathrm{ALS}=0.85 \%$, control $=4.34 \%$, $\mathrm{OR}=0.19)$; COPD $(\mathrm{ALS}=2.87 \%$, control $=11.53 \%, \mathrm{OR}=0.23)$; kidney disease $(\mathrm{ALS}=0.93 \%$, control $=2.86 \%, \mathrm{OR}=0.32$ ); adult asthma $(\mathrm{ALS}=4.89 \%$, control $=11.53 \%, \mathrm{OR}=0.39$ ); diabetes, including types I and II (ALS $=7.38 \%$, control $=$ $14.47 \%$, OR $=0.47)$; hypertension $(\mathrm{ALS}=36.34 \%$, control $=50.43 \%$, OR $=0.56$ ); obesity $($ ALS $=20.57 \%$, control $=30.17 \%, \mathrm{OR}=0.6)$; hyperlipidemia or hypercholesterolemia/dyslipidemia (ALS $=30.67 \%$, control $=41.69 \%$, $\mathrm{OR}=0.62)$; and thyroid disease, including hyper- and hypothyroidism $(\mathrm{ALS}=6.91 \%$, control $=8.70 \%$, OR $=$ $0.78)$.

\section{Discussion}

This is the first study to identify lower prevalence across multiple diseases in the same very large ALS patient population. However, these results generally sup- port the findings of previous smaller studies examining individual diseases in ALS patients $[1,2,6,20]$.

Other confounding factors potentially affecting antecedent disease prevalence include socioeconomics (income and education) and regular health care maintenance with a physician. Unfortunately, such data was not available for all subjects in this study. However, many additional studies have also examined the possible influence of these factors on condition prevalence in non-ALS populations [15-17]. The maximum confounds' bias (see Methods) on condition prevalence ranges from a factor of 1.2-2.0 (equivalent to an OR of 0.83-0.5 in this study), with an average factor of change equal to 1.5 (equivalent to an OR of 0.66). Thus, the calculated maximum possible predicted impact of confounds on the results of this ALS population is a factor of $2(\mathrm{an} O R=0.5)$. Therefore, any condition with an $\mathrm{OR}<0.5$ would still be significantly less in this ALS population irrespective of the unlikely presence of maximum possible confound bias.

Notably, 7 of the 11 assessed conditions have an OR $<0.5$, including arthritis, neurological disease, liver disease, COPD, kidney disease, asthma and diabetes. This suggests that even in the extreme case of maximum possible bias, such potential confounds would not affect our conclusions about these conditions. Additionally, it is worth noting that 2 of the 4 conditions with OR $>0.5$ (hypertension at 0.56 and obesity at 0.60 ) have been previously shown in multiple studies to have a lower prevalence in ALS patients $[1,2,6,9]$. The prevalence of hyperlipidemia in ALS patients $(\mathrm{OR}=0.62)$ remains controversial in the literature $[6,12]$, which could be potentially attributed to different studies' confounds or methods. Finally, other small studies $[10,11]$ also found that thyroid disease $(\mathrm{OR}=0.78)$ tends to be less prevalent in ALS but is not necessarily statistically less. In summary, we conclude that unexamined factors or confound biases are not responsible for our overall results as they are more likely no larger than a factor of 1.25 (OR of 0.8 ) in the population.

The magnitude of the odds ratios, with conditions like arthritis, non-ALS neurological disease, and liver disease being a factor of 4-7 times less prevalent in the ALS population, suggest possible protective mechanisms. 'Other disease as ALS protection' has been previously suggested. Conversely, another possibility is 'ALS as other disease protection', which has not been previously suggested. We discuss these two possibilities below.

Several have pointed to the possibility that other conditions, such as diabetes [9] or hyperlipidemia [21], could 
be biochemically neuroprotective to motoneurons. However, others have shown that having these conditions results in no change in ALS onset age or disease duration $[6,22]$. Thus, the validity of the 'disease as ALS protection' hypothesis remains unresolved.

Another possibility is that the underlying physiological pre-cursors of ALS could actually be protecting against other conditions prior to the onset of ALS symptoms, analogous to how one $S$ gene infers resistance to malaria without pathological consequence, while 2 copies result in the pathological sickle cell anemia phenotype [23]. We hypothesize that one possible 'ALS as disease protection' mechanism could be that, in some individuals, the underlying regulatory processes aggressively overreact to correct imbalances from homeostasis, making them 'hypervigilant' to perturbation (in control theory, referred to as a too-high feedback gain). Hypervigilant regulation would initially be overall protective, perhaps against an array of many different perturbing conditions, as long as stable control was maintained. However, motoneurons are already susceptible to changes in regulatory process delay due to their physical length (i.e., axons can be up to 1-meter in length) and a large span of regulatory time constants (e.g., axonal transport regulation is on the order of days to weeks, whereas calcium regulation is on the order of milliseconds). Regulatory delays, combined with the too high feedback gain(s) of hypervigilant regulation, could ultimately result in system instabilities, such as those identified in ALS transgenic mice [24], that could directly correspond to a symptomatic ALS phenotype.
This large-scale study of 1,288 ALS patients, combined with the results of similar smaller-scale studies, provide overwhelming evidence that antecedent disease prevalence is less in ALS. However, which condition(s) are protecting whom from what? This question remains unanswered. Clearly more research is needed to assess antecedent health in ALS and corresponding possible protective mechanisms.

\section{Author Contributions}

C. Mitchell designed the study, drafted the first manuscript, and contributed to data acquisition, statistical analysis, data interpretation, and revision of the manuscript. S. Hollinger contributed to data acquisition, statistical analysis, and revision of the manuscript. S. Goswami contributed to data acquisition and revision of the manuscript. M. Polak contributed to data acquisition and revision of the manuscript. R. Lee contributed to statistical analysis, data interpretation and manuscript revision. J. Glass contributed data acquisition, data interpretation, and manuscript revision.

\section{Funding}

USA National Institute of Health grants NS081426 and NS069616 to CSM. The funding agencies had no role in the design and conduct of the study, collection, management analysis and interpretation of the data; preparation, review or approval of the manuscript; or decision to submit the manuscript for publication.

\section{Disclosure Statement}

The authors have no competing interests to disclose.

\section{References}

1 Armon C, Kurland LT, O'Brien PC, Mulder DW: Antecedent medical diseases in patients with amyotrophic lateral sclerosis. A population-based case-controlled study in Rochester, Minn, 1925 through 1987. Arch Neurol 1991;48:283-286.

-2 Sutedja NA, van der Schouw YT, Fischer K, Sizoo EM, Huisman MH, Veldink JH, Van den Berg LH: Beneficial vascular risk profile is associated with amyotrophic lateral sclerosis. J Neurol Neurosurg Psychiatry 2011;82: 638-642.

3 Bouteloup C, Desport JC, Clavelou P, Guy N, Derumeaux-Burel H, Ferrier A, Couratier P: Hypermetabolism in ALS patients: an early and persistent phenomenon. J Neurol 2009; 256:1236-1242.

-4 Chio A, Benzi G, Dossena M, Mutani R, Mora G: Severely increased risk of amyotrophic lateral sclerosis among Italian pro- fessional football players. Brain 2005; 128 : 472-476.

5 Pagani MR, Gonzalez LE, Uchitel OD: Autoimmunity in amyotrophic lateral sclerosis: past and present. Neurol Res Int 2011;2011: 497080.

-6 Korner S, Kollewe K, Ilsemann J, Muller-Heine A, Dengler R, Krampfl K, Petri S: Prevalence and prognostic impact of comorbidities in amyotrophic lateral sclerosis. Eur J Neurol 2013;20:647-654.

7 O'Reilly EJ, Wang H, Weisskopf MG, Fitzgerald KC, Falcone G, McCullough ML, Thun M, Park Y, Kolonel LN, Ascherio A: Premorbid body mass index and risk of amyotrophic lateral sclerosis. Amyotroph Lateral Scler Frontotemporal Degener 2013;14:205-211.

-8 Turner MR, Goldacre R, Ramagopalan S, Talbot K, Goldacre MJ: Autoimmune disease preceding amyotrophic lateral sclerosis: an epidemiologic study. Neurology 2013;81: $1222-1225$.

$\checkmark 9$ Jawaid A, Salamone AR, Strutt AM, Murthy SB, Wheaton M, McDowell EJ, Simpson E, Appel SH, York MK, Schulz PE: ALS disease onset may occur later in patients with premorbid diabetes mellitus. Eur J Neurol 2010; 17:733-739.

10 Iwasaki Y, Kinoshita M, Ikeda K, Takamiya K, Shiojima T: Amyotrophic lateral sclerosis and thyroid function. J Neurol 1989;236:373-374.

11 Kiessling WR: Thyroid function in 44 patients with amyotrophic lateral sclerosis. Arch Neurol 1982;39:241-242.

12 Ikeda K, Hirayama T, Takazawa T, Kawabe K, Iwasaki Y: Relationships between disease progression and serum levels of lipid, urate, creatinine and ferritin in Japanese patients with amyotrophic lateral sclerosis: a cross-sectional study. Intern Med 2012;51:1501-1508. 
13 National Health Interview Survey, 2012. National Center for Health Statistics, US Center for Disease Control, 2014.

14 Khishchenko N, Allen KD, Coffman CJ, Kasarskis EJ, Lindquist JH, Morgenlander JC, Norman BB, Oddone EZ, Rozear MP, Sabet A, Sams L, Bedlack RS: Time to diagnosis in the national registry of veterans with amyotrophic lateral sclerosis. Amyotroph Lateral Scler 2010;11:125-132.

15 Baldassari AR, Cleveland RJ, Callahan LF: Independent associations of childhood and current socioeconomic status with risk of selfreported doctor-diagnosed arthritis in a family-medicine cohort of North-Carolinians. BMC Musculoskelet Disord 2013;14:327.

16 Eisner MD, Blanc PD, Omachi TA, Yelin EH, Sidney S, Katz PP, Ackerson LM, Sanchez G, Tolstykh I, Iribarren C: Socioeconomic status, race and COPD health outcomes. J Epidemiol Community Health 2011;65:26-34.
17 Mosca I, Bhuachalla BN, Kenny RA: Explaining significant differences in subjective and objective measures of cardiovascular health: evidence for the socioeconomic gradient in a population-based study. BMC Cardiovasc Disord 2013;13:64.

18 Andersen PM: Genetic factors in the early diagnosis of ALS. Amyotroph Lateral Scler Other Motor Neuron Disord 2000;1(suppl 1):S31-S42.

19 Chio A, Canosa A, Gallo S, Cammarosano S, Moglia C, Fuda G, Calvo A, Mora G, PARALS group: ALS clinical trials: do enrolled patients accurately represent the ALS population? Neurology 2011;77:1432-1437.

20 van Doormaal PT, Gallo A, van Rheenen W, Veldink JH, van Es MA, van den Berg LH: Amyotrophic lateral sclerosis is not linked to multiple sclerosis in a population based study. J Neurol Neurosurg Psychiatry 2013;84:940941.
21 Dupuis L, Corcia P, Fergani A, Gonzalez De Aguilar JL, Bonnefont-Rousselot D, Bittar R, Seilhean D, Hauw JJ, Lacomblez L, Loeffler JP, Meininger V: Dyslipidemia is a protective factor in amyotrophic lateral sclerosis. Neurology 2008;70:1004-1009.

22 Dedic SI, Stevic Z, Dedic V, Stojanovic VR, Milicev M, Lavrnic D: Is hyperlipidemia correlated with longer survival in patients with amyotrophic lateral sclerosis? Neurol Res 2012;34:576-580.

23 Cyrklaff M, Sanchez CP, Kilian N, Bisseye C, Simpore J, Frischknecht F, Lanzer M: Hemoglobins $\mathrm{S}$ and $\mathrm{C}$ interfere with actin remodeling in Plasmodium falciparum-infected erythrocytes. Science 2011;334:1283-1286.

24 Mitchell CS, Lee RH: Dynamic meta-analysis as a therapeutic prediction tool for amyotrophic lateral sclerosis; in Maurer M (ed): Amytrophic Lateral Sclerosis. InTech, 2012, pp 59-80. 